Pacific Journal of Mathematics

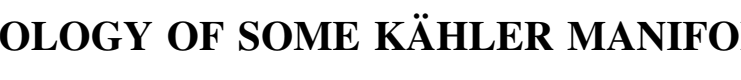




\title{
TOPOLOGY OF SOME KÄHLER MANIFOLDS
}

\author{
K. SRINivasacharyulu
}

\begin{abstract}
Goldberg and Bishop have shown that a homogeneous Kähler manifold of positive holomorphic curvature is isometric to the complex projective space with the usual metric. The aim of this note is to prove that such a Kähler manifold is isomorphic to the complex projective space.
\end{abstract}

We recall that a compact Kähler manifold $M$ of positive (resp. negative) holomorphic sectional curvature is always algebraic by a well-known theorem of Kodaira since its Ricci curvature is positive (resp. negative) [5]. The positively curved compact Kähler manifolds are simplyconnected (cf p. 528, [3]) and their second Betti number $b_{2}$ is equal to one [2]. In $\S 2$, we prove that the first Betti number $b_{1}$ of a negatively curved compact Kähler surface is always zero.

In what follows, we assume that $M$ is homogeneous and its group of automorphisms acts effectively; recall that a homogeneous Kähler manifold is complete.

THEOREM. A homogeneous Kähler n-manifold $M$ of positive holomorphic curvature is isomorphic to $P C_{n}$.

Proof. It is well-known (p. 527, [3]) that a complete Kähler manifold $M$ of positive holomorphic curvature is compact and is simplyconnected; moreover, its second Betti number is 1 [2] and its EulerPoincaré characteristic $E$ is positive (Theorem 2, [9]). Thus we may assume that $M=K / L$ is the quotient of a compact semi-simple Lie group by a closed subgroup by a well-known theorem of Montgomery. It is well-known that $L$ is of maximal rank in $K$ and $K$ has trivial center. Moreover, $L$ is the centralizer of a 1-parameter subgroup of $K$ [9]. We first prove that $K$ is simple; in fact, let us assume that $K=K_{1} \times \cdots \times K_{m}$ with $K_{i}$ compact, connected and simple. Since $L$ is of maximal rank, we have $L=L_{1} \times \cdots \times L_{m}$, where $L_{i} \subset K_{i}$, $i=1,2, \cdots, m$. Thus $M=\Pi_{1}^{m}\left(K_{i} / L_{i}\right)$ which is impossible in view of the fact $b_{2}(M)=1$. Consider now the fibration of $K$ onto $K / L$ with fibre $L$; since $K$ is simple, the transgression defines an isomorphism of $H^{1}(L)$ onto $H^{2}(K / L)$ where the cohomology is taken with real coefficients. But $H^{1}(L)$ is isomorphic to the center of $L$; since $b_{2}(K / L)=1$, we see that the center of $L$ is of dimension one. $K$ being effective, the isotropy representation of $L$ is faithful and hence the linear isotropy group is irreducible; consequently $K / L$ is irreducible hermitian symmetric (cf., p. 52, [4] and [8]). But the only irreducible 
compact hermitian symmetric space of positive holomorphic curvature in the list of $\hat{E}$. Cartan is the complex projective space.

REMARK. In fact we have shown above the following more general result: Let $M$ be a compact, simply-connected homogeneous complex manifold whose Euler-Poincaré characteristic is positive; if its second Betti number is one, then $M$ is isomorphic to an irreducible hermitian symmetric space (cf. Théorème 1, C.R.A.S. Paris 252, pp. 3377-3378 (1961), and [6]).

2. Let $D$ be an irreducible symmetric bounded domain of one of the following types: $I_{m, m^{\prime}}\left(m>m^{\prime}>6\right), I I_{m}(m>7), I I I_{m}(m>7)$ or IV. If $M$ is a compact quotient of $D$ by a properly discontinuous subgroup of automorphisms of $D$, it is well known that $b_{1}(M)=0$ and $b_{2}(M)=1$. In fact, we have the following result essentially due to Remmert-Van de Ven (cf. p. 456, [7]):

Proposition 1. Let $M$ be a compact Kähler manifold of dimension greater than one; if $b_{2}=1$, then its first Betti number is zero.

Proof. Suppose that $b_{1}=2 q, q=h^{1,0}(M)$, is positive; let $A(M)$ denote the Albanese manifold of $M$ and let $\phi: M \rightarrow A(M)$ be the nonconstant holomorphic onto projection. Since $b_{2}=1$, we have $h^{2,0}(M)=0$ and hence $M$ is algebraic by Kodaira's theorem. Therefore $\operatorname{dim} M=$ $\operatorname{dim} A(M)$ by Theorem 1.3 of [7]; let $\omega$ be a nonzero holomorphic 2form on $A(M)$; then $\phi^{*} \omega$ is a nonzero holomorphic 2-form on $M$, a contradiction.

In fact, we can prove the following result for negatively curved Kähler surfaces which generalizes a result of [3]:

Proposition 2. Let $M$ be a compact Kähler surface of negative Ricci curvature; then its first Betti number is zero.

Proof. Since the Ricci curvature is negative, we have $H^{q}(M$, $\left.\Omega^{p}(K)\right)=0$ if $p+q=1$ by a result of Akizuki-Nakano [1]; consequently, $H^{1}\left(M, \Omega^{0}(K)\right)=H^{0,1}(K)=0$ by Dolbeault's theorem. But $H^{0,1}(K)=H^{0,1}\left(M, K \otimes K^{*}\right)=H^{0,1}(M, 1)$ where 1 denote the trivial line bundle, by the duality theorem of Serre. Thus $h^{0,1}=\operatorname{dim} H^{0,1}(M, 1)=0$ and hence $b_{1}=0$.

REMARK. Note that the Euler-Poincaré characteristic of such a surface is positive (cf., [3]). 


\section{BIBLIOGRAPHY}

1. Y. Akizuki and S. Nakano, Note on Kodaira-Spencer's proof of Lefschetz theorems, Proc. of the Jap. Acad. 30 (1954), 266-272.

2. R. L. Bishop and S. I. Goldberg, On the second cohomology group of a Kähler manifold of positive curvature, Proc. Amer. Math. Soc. 16 (1965), 119-222.

3. - Some implications of the generalized Gauss-Bonnet theorem, Trans. Amer. Math. Soc. 112 (1964), 508-535.

4. É. Cartan, La théorie des groupes finis et continues et l'analysis situs, Mémorial Sci. Math., Paris, 1930.

5. T. Frankel, Manifolds with positive curvature, Pacific J. Math. 11 (1961), 165-174.

6. R. Remmert and A. Borel, Über kompakte homogene kählersche Mannigfaltigkeiten, Math. Annalen 145 (1962), 429-439.

7. R. Remmert and T. Van de Ven, Uber holomorphe Abbildungen projekti-algebraischen Mannigfaltigkeiten auf komplexe Räume Math. Ann. 142 (1961), 453-486.

8. J. de Siebenthal et A. Borel, Les sous-groupes fermés de rang maximum des groupes de Lie clos, commentari Math. Helv. 23 (1949), 202-221.

9. H. C. Wang, Some geometrical aspects of coset spaces of Lie groups, Proc. Inter. Congress of Math. 1958 (1960), 500-509.

Received February 29, 1966.

UNIVERSité DE MONTRÉAL

MONTRÉAL, CANADA 



\section{PACIFIC JOURNAL OF MATHEMATICS}

\section{EDITORS}

\section{H. ROYDEN}

Stanford University

Stanford, California

J. P. JANS

University of Washington

Seattle, Washington 98105

\section{J. DUGUNDJI}

Department of Mathematics

Rice University

Houston, Texas 77001

RICHARD ARENS

University of California

Los Angeles, California 90024

ASSOCIATE EDITORS

E. F. BECKENBACH

B. H. NeumanN

F. WoLF

K. YosidA

\section{SUPPORTING INSTITUTIONS}

\author{
UNIVERSITY OF BRITISH COLUMBIA \\ CALIFORNIA INSTITUTE OF TECHNOLOGY \\ UNIVERSITY OF CALIFORNIA \\ MONTANA STATE UNIVERSITY \\ UNIVERSITY OF NEVADA \\ NEW MEXICO STATE UNIVERSITY \\ OREGON STATE UNIVERSITY \\ UNIVERSITY OF OREGON \\ OSAKA UNIVERSITY \\ UNIVERSITY OF SOUTHERN CALIFORNIA
}

\author{
STANFORD UNIVERSITY \\ UNIVERSITY OF TOKYO \\ UNIVERSITY OF UTAH \\ WASHINGTON STATE UNIVERSITY \\ UNIVERSITY OF WASHINGTON \\ AMERICAN MATHEMATICAL SOCIETY \\ CHEVRON RESEARCH CORPORATION \\ TRW SYSTEMS \\ NAVAL ORDNANCE TEST STATION
}




\section{Pacific Journal of Mathematics}

\section{Vol. 23, No. 1 \\ March, 1967}

M. J. C. Baker, A spherical Helly-type theorem ................... 1

Robert Morgan Brooks, On locally m-convex*-algebras.............. 5

Lindsay Nathan Childs and Frank Rimi DeMeyer, On automorphisms of separable algebras ...................................

Charles L. Fefferman, A Radon-Nikodym theorem for finitely additive set

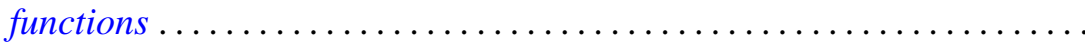

Magnus Giertz, On generalized elements with respect to linear

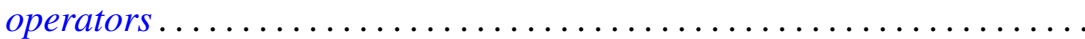

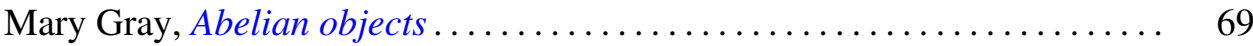

Mary Gray, Radical subcategories.............................. 79

John A. Hildebrant, On uniquely divisible semigroups on the two-cell . . . . . 91

Barry E. Johnson, AW*-algebras are $\mathrm{QW}^{*}$-algebras ............... 97

Carl W. Kohls, Decomposition spectra of rings of continuous functions . . . . 101

Calvin T. Long, Addition theorems for sets of integers .............. 107

Ralph David McWilliams, On $w^{*}$-sequential convergence and quasi-reflexivity ................................... 113

Alfred Richard Mitchell and Roger W. Mitchell, Disjoint basic

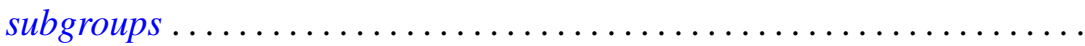

John Emanuel de Pillis, Linear transformations which preserve hermitian and positive semidefinite operators .

Qazi Ibadur Rahman and Q. G. Mohammad, Remarks on Schwarz's lemma

Neal Jules Rothman, An $L^{1}$ algebra for certain locally compact topological semigroups ...

F. Dennis Sentilles, Kernel representations of operators and their adjoints ...

D. R. Smart, Fixed points in a class of sets

K. Srinivasacharyulu, Topology of some Kähler manifolds

Francis C.Y. Tang, On uniqueness of generalized direct decompositions .

171 Albert Chapman Vosburg, On the relationship between Hausdorff dimension and metric dimension . 